\title{
First-line latanoprost therapy in ocular hypertension or open-angle glaucoma patients: a 3-month efficacy analysis stratified by initial intraocular pressure
}

Philippe Denis $^{1^{*}}$, Christophe Baudouin ${ }^{2}$, Alain Bron ${ }^{3}$, Jean-Philippe Nordmann ${ }^{4}$, Jean Paul Renard ${ }^{5}$, Jean François Rouland ${ }^{6}$, Eric Sellem ${ }^{7}$, Mourad Amrane ${ }^{8}$

\begin{abstract}
Background: Prospective, multicenter, randomized, double-masked trials have shown latanoprost instilled once daily to be at least as effective as and generally superior to timolol administered twice daily and to be as effective as other frequently prescribed prostaglandin analogues. This study prospectively assessed the efficacy of latanoprost monotherapy in a large cohort of treatment-naive patients with a broad range of baseline intraocular pressure (IOP) levels treated in actual clinical practice settings.

Methods: This prospective, open-label, multicenter, uncontrolled, phase IV study included treatment-naive ocular hypertension or open-angle glaucoma subjects initiating latanoprost once daily (evening). IOP levels were measured at baseline and after 1 and 3 months. The primary efficacy outcome was mean change in IOP from baseline to month 3. Analyses were stratified by baseline IOP: $\geq 20$ and $<24 \mathrm{mmHg} v s \geq 24 \mathrm{mmHg}$.

Results: Efficacy analyses (intent to treat) included 572 subjects: 20 to $<24 \mathrm{mmHg}$ group, $\mathrm{N}=252 ; \geq 24 \mathrm{mmHg}$ group, $\mathrm{N}=320$. Mean baseline IOP levels were $22.2 \pm 0.9 \mathrm{mmHg}$ and $26.7 \pm 2.8 \mathrm{mmHg}$, respectively. At month 3 , significant IOP reductions were seen in both groups ( $<0.0001$, within-group differences); reductions were smaller in the 20 to $<24 \mathrm{mmHg}$ group $(-6.3 \pm 2.4$ vs $-9.2 \pm 3.7 \mathrm{mmHg}$, respectively; $-28.0 \pm 10.6 \%$ vs $-34.1 \pm 11.9 \%$, respectively). An IOP reduction of $\geq 30 \%$ from baseline to month 3 was noted in $48.4 \%$ and $65.6 \%$ of subjects, respectively $(p<0.0001)$. At month 3 , targets IOPs of $\leq 18 \mathrm{mmHg}$ were achieved by $\geq 70 \%$ of subjects in both groups. Latanoprost was well tolerated with an adverse event profile similar to that reported in the literature.
\end{abstract}

Conclusions: This "real world" study found once-daily latanoprost to be effective and safe in treatment-naive ocular hypertension or open-angle glaucoma patients. Patients with baseline IOP levels of 20 to $<24 \mathrm{mmHg}$ as well as $\geq 24 \mathrm{mmHg}$ benefitted from initial latanoprost therapy.

Trial Registration: Trial Registration Number: NCT00647101

\section{Background}

Glaucoma is among the leading causes of blindness worldwide [1], and elevated intraocular pressure (IOP) is a major risk factor for progression of both ocular hypertension and glaucoma [2]. Reducing IOP prevents or delays the onset of open-angle glaucoma in patients

\footnotetext{
* Correspondence: philippe.denis@chu-lyon.fr
'Ophthalmology Department, Hôpital Edouard Herriot, 5, Place d'Arsonval,

* Correspondence: philippe.denis@chu-lyon.fr
'Ophthalmology Department, Hôpital Edouard Herriot, 5, Place d'Arsonval, 690437 Lyon Cedex 03, France
}

(c) 2010 Denis et al; licensee BioMed Central Ltd. This is an Open Access article distributed under the terms of the Creative Commons Attribution License (http://creativecommons.org/licenses/by/2.0), which permits unrestricted use, distribution, and reproduction in any medium, provided the original work is properly cited. among those with open-angle glaucoma [4-8].

Treatment to reduce IOP levels commonly begins with topical ocular hypotensive agents. Among these, latanoprost, which became available in 1996 and was approved by the European Agency for the Evaluation of Medicinal Products as first-line treatment in March 2002, is one of the most frequently prescribed and has been shown to be at least as effective as or superior to the beta-blocker timolol [9-13]. A pooled analysis [13] of data from eight 
prospective, randomized, parallel-group trials (five of which were double-masked) found latanoprost reduced diurnal IOP levels statistically significantly more than timolol in a global population of ocular hypertension and open-angle glaucoma patients $(\mathrm{N}=1389)$. Subgroup analyses demonstrated that latanoprost was effective across racial and ethnic groups and resulted in similar mean diurnal IOP reductions in those with and without prior ocular hypotensive treatment other than prostaglandins.

While findings of individual prospective, randomized, parallel-group, double-masked clinical trials - the gold standard for evaluating new therapies - and pooled analyses across trials provide convincing evidence of the efficacy and safety of latanoprost, their designs are restrictive and do not reflect conditions found in routine clinical practice settings. In particular, these trials generally recruited both treatment-naive and previously treated patients; set strict inclusion and exclusion criteria, often stipulating that baseline IOP levels be $\geq 22$ mmHg; established a washout period for patients under treatment at screening; and required frequent patient monitoring. Thus, it remains of interest to prospectively assess the efficacy of latanoprost monotherapy in a large cohort of treatment-naive ocular hypertension and open-angle glaucoma patients with a broader range of baseline IOP levels treated in actual clinical practice settings.

The primary purpose of the present study was to conduct such an assessment in patients treated in ophthalmology practices in France who were followed for 3 months after being prescribed first-line latanoprost $0.005 \%$ administered once daily. In order to determine whether response to latanoprost differs by presenting IOP level, it was predetermined that analyses would be stratified by baseline IOP dichotomized as $\geq 20$ and $<24 \mathrm{mmHg}$ (20 to $<24 \mathrm{mmHg}$ group) $v s \geq 24 \mathrm{mmHg}$ ( $\geq 24 \mathrm{mmHg}$ group). The cut point of $24 \mathrm{mmHg}$ was considered to be clinically relevant and to distinguish roughly between those with very high $v s$ moderately high IOP levels. The Collaborative Normal-Tension Glaucoma Study [14] included only patients with no recorded IOP over $24 \mathrm{mmHg}$ in either eye at screening.

\section{Methods}

\section{Study design}

This was a prospective, 3-month, open-label, multicenter, uncontrolled, phase IV study (NCT00647101) conducted in 258 ophthalmology practices in France. The final protocol and informed consent documents were reviewed and approved by the Independent Ethics Committee (Comité Consultatif de Protection des Personnes se prêtant à une Recherche Biomédicale de Lyon, France). The study complied with local French laws, with the International Conference on Harmonization Guidelines, and with the Declaration of Helsinki Guidelines. Written informed consent was obtained from each subject prior to study enrollment. We certify that all applicable institutional and governmental regulations concerning the ethical use of human volunteers were followed during this research.

\section{Subjects}

Eligible subjects were at least 18 years of age and had a baseline (initial visit) IOP of $\geq 20 \mathrm{mmHg}$ related to a diagnosis of unilateral or bilateral ocular hypertension or open-angle glaucoma (primary open-angle glaucoma, pseudoexfoliation glaucoma, or pigmentary glaucoma) following a visual field examination. Only subjects who, in the investigator's opinion, required initiation of ocular hypotensive treatment and who had never been treated for ocular hypertension or open-angle glaucoma were eligible. In an effort to balance enrollment across IOP strata, investigators were instructed to enroll one subject in each stratum before enrolling additional subjects in either stratum.

Subjects were excluded if they had traumatic, inflammatory, or neovascular glaucoma; had any ophthalmic or systemic disorder, including uncontrolled asthma, that, in the opinion of the investigator, would prevent study entry; had a known hypersensitivity to benzalkonium chloride or any other component of latanoprost; or had participated in another clinical trial within 30 days prior to the enrollment visit. In addition, women of childbearing potential who were not using adequate contraceptive methods or who were pregnant or nursing were not included.

\section{Treatment and assessments}

Subjects were assessed for eligibility at the baseline visit. Demographic information, ocular and medical histories, and concomitant medications were documented; bestcorrected visual acuity was measured; biomicroscopy, ophthalmoscopy, an eyelid examination, and fundoscopy were performed; and stage of open-angle glaucoma was classified as early, moderate, or severe. A visual field examination was conducted at baseline or within the following 1 month unless such an examination had been conducted during the 6 months prior to baseline. IOP was measured prior to pupil dilation using an air-pulsed tonometer (three measurements; mean IOP value used in analyses) or a calibrated Goldmann applanation tonometer (single measurement).

All subjects were prescribed latanoprost $0.005 \%$ to be instilled once daily in the evening. Other ocular hypotensive medications were prohibited during the study.

Follow-up visits were scheduled after 1 and 3 months of latanoprost treatment. At each visit, concomitant medications were recorded, and biomicroscopy, ophthalmoscopy, 
and an eyelid examination were performed. IOP was measured at the same time ( \pm 1 hour) as at the baseline visit and prior to pupil dilation. The same calibrated device (air-pulsed tonometer or Goldmann applanation tonometer) was used for the same subject at all visits. As at the baseline visit, three measurements were made for subjects evaluated with an air-pulsed tonometer (mean IOP value used in analyses) and a single measurement was made for those assessed with a Goldmann applanation tonometer. At month 3, best-corrected visual acuity was measured and fundoscopy was performed. At the 1 and 3 month visits, subjects were asked a single question about how often they forgot to take their latanoprost, and responses were classified as "took every day," "rarely forgot," and "forgot sometimes."

All adverse events, whether observed or volunteered, were recorded at each follow-up visit. The severity of events (mild, moderate, or severe) and the investigator's opinion about whether the event was related to study drug were recorded. Serious adverse events were defined as those that were life-threatening, required inpatient hospitalisation/prolongation of hospitalisation, caused persistent or significant disability/incapacity, or resulted in congenital anomaly/birth defect or death. Adverse events were followed until they resolved or stabilised. As part of adverse event reporting, investigators were instructed to question patients concerning whether they had used any bottle of latanoprost beyond its expiration date, i.e., for $>28$ days after opening. Any such extended use was reported as an adverse event, and the investigator also documented whether any related clinical problem had occurred.

\section{Endpoints and analyses}

Efficacy analyses used only IOP measurements of one study eye per subject. If both eyes of a subject were eligible, the eye with the highest IOP at baseline was considered the study eye; if the baseline IOP was the same in both eyes, the right eye was considered the study eye.

The primary efficacy endpoint was mean change in IOP from baseline to month 3 . Secondary efficacy endpoints included mean change in IOP from baseline to month 1; mean percent change in IOP from baseline to months 1 and 3; percentage of subjects achieving $\geq 10 \%$ and $\geq 30 \%$ reductions in IOP from baseline to month 3 ; and percentage of subjects achieving target IOP levels of $\leq 21, \leq 18$, and $\leq 15 \mathrm{mmHg}$ at months 1 and 3 .

Efficacy analyses were stratified by baseline IOP level (20 to $<24 v s \geq 24 \mathrm{mmHg}$ ) and were conducted in the intent-to-treat population which included all subjects who met entry criteria, who instilled $\geq 1$ dose of study medication, and for whom a baseline IOP measurement and at least 1 on-treatment IOP measurement was recorded. In efficacy analyses, the last observation carried forward method was used to impute missing data. Safety analyses included all subjects who instilled $\geq$ 1 dose of study medication.

The statistical significance of within-stratum changes in mean IOP levels from baseline to months 1 and 3 was evaluated using paired $t$ tests. The significance of between-strata differences in frequencies of subjects achieving prespecified percentage IOP reductions and target IOP levels was assessed using chi-square tests. The two-sided significance level was set at the 0.05 level.

Multiple correspondence analyses were performed to identify factors predicting response to treatment defined as $\mathrm{a} \geq 30 \%$ reduction in IOP from baseline to month 3 . Potential predictors included IOP stratum (20 to $<24 v s$ $\geq 24 \mathrm{mmHg})$; age $(<55,55$ to $65,>65$ years $)$; gender; ocular hypertension $v s$ open-angle glaucoma; myopia (>-6 diopters, $\leq-6$ diopters, no myopia) presence/ absence of diabetes, sleep disorders, use of antihypertensive medication, obesity, and family history of ocular hypertension or glaucoma; tobacco use within prior year (yes/no); and compliance (good/poor). Forward stepwise logistic regression then was used to determine which potentially significant predictors provided the most explanatory power with regard to treatment response.

The sample size calculation was based on requirements of the multiple correspondence analyses using the formula $\mathrm{N}=\Pi_{\mathrm{i}}=1$ à $\mathrm{n}(\mathrm{M}(\mathrm{i}))$ where $\mathrm{M}(\mathrm{i})$ is the number of modalities for variable $i$ and $n$ is the number of variables studied simultaneously. It was determined a priori that variables reflecting subject and disease characteristics, cardiovascular risk factors, and ophthalmic history would be entered into analyses. The target number of subjects to be enrolled was 768 .

\section{Results}

\section{Study population}

Between 22 December 2003 and 16 February 2005, 600 subjects with ocular hypertension or open-angle glaucoma were enrolled, 270 subjects in the 20 to $<24$ $\mathrm{mmHg}$ group and 330 subjects in the $\geq 24 \mathrm{mmHg}$ group (Figure 1). In all, 590 subjects received $\geq 1$ dose of latanoprost and were included in safety analyses $(20$ to $<24 \mathrm{mmHg}$ group, $\mathrm{N}=262$; $\geq 24 \mathrm{mmHg}$ group, $\mathrm{N}=328$ ). The ITT population, which excluded 2 subjects who did not meet study entry criteria and 16 for whom no valid postbaseline IOP measurement was recorded, included 252 subjects in the 20 to $<24 \mathrm{mmHg}$ group and 320 subjects in the $\geq 24 \mathrm{mmHg}$ group. In all, 553 subjects completed the study; the major reasons for premature withdrawal among the 590 treated subjects were adverse events and "other reasons" ( $n=13 / 37$ and $\mathrm{n}=11 / 37$, respectively; Figure 1).

Demographic and clinical characteristics of subjects at baseline are summarized in Table 1 . The mean age of 


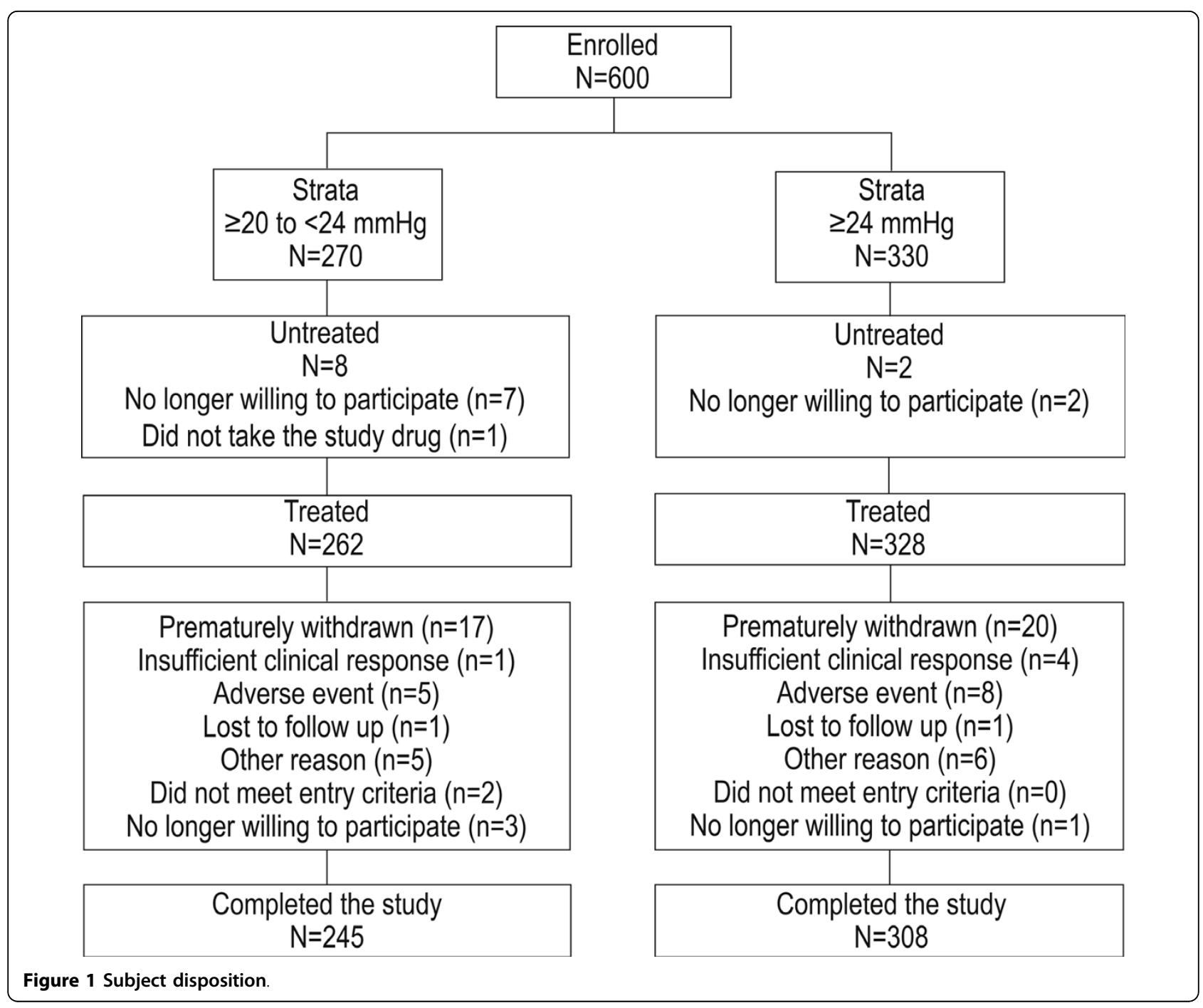

subjects in the two baseline IOP strata was similar, approximately 59 years; a larger percentage of those in the $\geq 24 \mathrm{mmHg}$ group were male. More subjects in the $\geq$ $24 \mathrm{mmHg}$ group were diagnosed with open-angle glaucoma, and, among those with glaucoma, a larger percentage in that group had disease classified as "severe."

Exposure to latanoprost was similar between groups: $93.1 \pm 22.0$ days in the 20 to $<24 \mathrm{mmHg}$ group and $91.6 \pm 18.3$ days in the $\geq 24 \mathrm{mmHg}$ group. The majority of subjects reported high levels of compliance with once-daily latanoprost, with $98 \%$ in each group reporting that they took the medication either every day or that they "rarely" forgot.

\section{Efficacy}

At month 3, mean IOP levels had decreased from baseline by $-6.3 \pm 2.4 \mathrm{mmHg}$ in the 20 to $<24 \mathrm{mmHg}$ group and by $-9.2 \pm 3.7 \mathrm{mmHg}$ in the $\geq 24 \mathrm{mmHg}$ group ( $\mathrm{p}<$ 0.0001 for each within-group comparison; Table 2 ).
Mean IOP levels decreased rapidly from baseline to month 1 and remained stable through month 3 with percent IOP changes of $-27.8 \pm 10.3 \%$ and $-28.0 \pm$ $10.6 \%$, respectively, in the 20 to $<24 \mathrm{mmHg}$ group and $-32.9 \pm 10.6 \%$ and $-34.1 \pm 11.9 \%$, respectively, in the $\geq$ $24 \mathrm{mmHg}$ group.

Similarly large percentages of subjects achieved $\geq 10 \%$ IOP reductions from baseline to month 3 in both groups: $94.1 \%$ in the 20 to $<24 \mathrm{mmHg}$ group and $96.9 \%$ in the $\geq 24 \mathrm{mmHg}$ group $(\mathrm{p}=0.10$; Table 2$)$. A significantly smaller percentage of those in the 20 to $<24$ $\mathrm{mmHg}$ group achieved IOP reductions of $\geq 30 \%$ by month 3 (48.4\% vs $65.6 \%$, respectively; $\mathrm{p}<0.0001)$. In contrast, significantly smaller percentages of those in the higher IOP group achieved IOP levels $\leq 21, \leq 18$, or $\leq$ $15 \mathrm{mmHg}$ at either months 1 or 3 ( $\mathrm{p}<0.001$ for each between-group comparison; Figure 2). It is notable that $70 \%$ of subjects in the $\geq 24 \mathrm{mmHg}$ group achieved IOP levels of $\leq 18 \mathrm{mmHg}$ by month 3 . 
Table 1 Baseline demographic and clinical characteristics, ITT population*

\begin{tabular}{|c|c|c|}
\hline \multirow[b]{2}{*}{ Characteristic } & \multicolumn{2}{|c|}{ Baseline IOP } \\
\hline & $\begin{array}{c}20 \text { to }<24 \mathrm{mmHg} \\
\mathrm{N}=252\end{array}$ & $\begin{array}{c}\geq 24 \mathrm{mmHg} \\
\mathrm{N}=320\end{array}$ \\
\hline \multicolumn{3}{|l|}{ Age, years } \\
\hline Mean \pm SD & $59.9 \pm 12.2$ & $59.1 \pm 11.8$ \\
\hline Gender, male & $117(46.4)$ & $174(54.4)$ \\
\hline \multicolumn{3}{|l|}{ Diagnosis } \\
\hline Ocular hypertension & $150(59.5)$ & $161(50.3)$ \\
\hline Open-angle glaucoma & $102(40.5)$ & $159(49.7)$ \\
\hline \multicolumn{3}{|l|}{ Open-angle glaucoma grade ${ }^{\dagger}$} \\
\hline Mild & $77(75.5)$ & $96(60.4)$ \\
\hline Moderate & $21(20.6)$ & $43(27.0)$ \\
\hline Severe & $4(3.9)$ & $20(12.6)$ \\
\hline \multicolumn{3}{|l|}{ Intraocular pressure } \\
\hline Mean (SD) & $22.2 \pm 0.9$ & $26.7 \pm 2.8$ \\
\hline \multicolumn{3}{|l|}{ Family history of ocular } \\
\hline hypertension or glaucoma & $85(33.7)$ & $73(22.8)$ \\
\hline \multicolumn{3}{|l|}{ Body mass index } \\
\hline Mean (SD) & $25.0 \pm 3.9$ & $25.1 \pm 3.9$ \\
\hline \multicolumn{3}{|l|}{ Comorbidities $^{\ddagger}$} \\
\hline Diabetes & $17(8.7)$ & $33(13.3)$ \\
\hline Hypertension & $69(35.2)$ & $77(30.8)$ \\
\hline Sleep disorders & 39 (19.8) & $34(13.7)$ \\
\hline Myopia & $78(31.0)$ & $95(29.7)$ \\
\hline$<-12$ diopters & $1(1.3)$ & $3(3.2)$ \\
\hline Between -6 and -12 diopters & $9(11.5)$ & $13(13.7)$ \\
\hline$>-6$ diopters & $68(87.2)$ & $79(83.2)$ \\
\hline Tobacco use within prior year ${ }^{\S}$ & $55(28.1)$ & $83(33.3)$ \\
\hline
\end{tabular}

${ }^{*} \mathrm{n}(\%)$ unless otherwise noted.

${ }^{\dagger}$ Percentages based on number of subjects with open-angle glaucoma.

FPercentages based on number of subjects reporting presence/absence of comorbidities.

${ }^{\text {s}}$ Percentages based on numbers of subjects reporting use/no use of tobacco within prior year.

$\mathrm{ITT}=$ intent to treat; $\mathrm{SD}=$ standard deviation.

\section{Predictors of treatment response}

Initial multiple correspondence analyses of the full variable set identified six potential predictors of response to treatment (IOP reduction $\geq 30 \%$ between baseline and month 3): age, gender, initial IOP stratum, current diagnosis, family history of ocular hypertension or glaucoma, and myopia. The logistic regression model with 568 subjects retained only two of these variables: initial IOP stratum and myopia. Treatment response was less likely in subjects whose baseline IOP was 20 to $<24 \mathrm{mmHg}$ (adjusted risk ratio [95\% confidence interval [CI], 0.488 [0.346, 0.686]; $\mathrm{p}<0.001)$ and less likely in those with myopia ( $\leq-6$ diopters $v s$ none: adjusted risk ratio [95\% $\mathrm{CI}]: 0.576$ [0.391, 0.894]; $\mathrm{p}=0.0053$ and $>-6$ diopters $v s$ none: adjusted risk ratio [95\% CI]: 0.392 [0.175, 0.879]; $\mathrm{p}=0.0230)$.
Table 2 Intraocular pressure (IOP) at baseline and month $3(\mathrm{mmHg})$, ITT population

\begin{tabular}{|c|c|c|}
\hline & Base & e IOP \\
\hline & $\begin{array}{c}20 \text { to }<24 \\
\mathrm{mmHg} \\
\mathrm{N}=252\end{array}$ & $\begin{array}{c}\geq 24 \mathrm{mmHg} \\
\mathrm{N}=320\end{array}$ \\
\hline Baseline IOP, mm & & \\
\hline Mean \pm SD & $22.2 \pm 0.9$ & $26.7 \pm 2.8$ \\
\hline Month $3 \mathrm{IOP}, \mathrm{mm}$ & & \\
\hline Mean \pm SD & $16.0 \pm 2.3$ & $17.5 \pm 3.2$ \\
\hline $\begin{array}{l}\text { IOP change from } \\
\mathrm{mmHg}\end{array}$ & & \\
\hline Mean \pm SD & $-6.3 \pm 2.4$ & $-9.2 \pm 3.7$ \\
\hline p-value* & $<0.0001$ & $<0.0001$ \\
\hline $\begin{array}{l}\% \text { change in IOP } \\
\text { month } 3\end{array}$ & & \\
\hline Mean \pm SD & $-28.0 \pm 10.6$ & $-34.1 \pm 11.9$ \\
\hline $\begin{array}{l}\geq 10 \% \text { IOP reduc } \\
\text { month } 3\end{array}$ & & \\
\hline $\mathrm{n}(\%)^{+}$ & $237(94.1)$ & $310(96.9)$ \\
\hline $\begin{array}{l}\geq 30 \% \text { IOP redue } \\
\text { month } 3\end{array}$ & & \\
\hline$n(\%)^{\ddagger}$ & $122(48.4)$ & $210(65.6)$ \\
\hline
\end{tabular}

${ }^{*} \mathrm{p}$-value based on $t$ test for paired data.

${ }^{+} p=0.10$ for between-group difference; chi-square test.

${ }^{\ddagger} p<0.0001$ for between-group difference; chi-square test.

$\mathrm{ITT}=$ intent to treat; $\mathrm{SD}=$ standard deviation.

\section{Safety}

Among the 590 subjects in the safety population, 237 (40.2\%) reported $\geq 1$ adverse events. Adverse event profiles were similar in subjects in the two baseline IOP strata (Table 3). Note that $119 / 339$ (35.1\%) adverse events and 119/235 (50.6\%) treatment-related adverse events reflected subject report of latanoprost instillation from a bottle that had been opened for $>28$ days, which was documented as an adverse event; no ocular or systemic adverse event associated with use of latanoprost from an expired bottle was reported. In all, nine subjects reported 10 serious adverse events, none of which was considered related to study drug. No deaths were reported during the study.

The most frequent treatment-related ocular adverse event was conjuctival hyperemia, occurring in $10.7 \%$ $(28 / 262)$ and $8.5 \%(28 / 328)$ subjects in the 20 to $<24$ and $\geq 24 \mathrm{mmHg}$ groups, respectively (Table 4 ). Eye pain occurred in approximately $3 \%$ of subjects in each IOP stratum, and all other treatment-related ocular adverse events occurred in $<2 \%$ of subjects.

\section{Discussion}

Short-term, prospective multicenter, randomized, double-masked trials have shown latanoprost instilled once daily to be at least as effective as and generally superior 


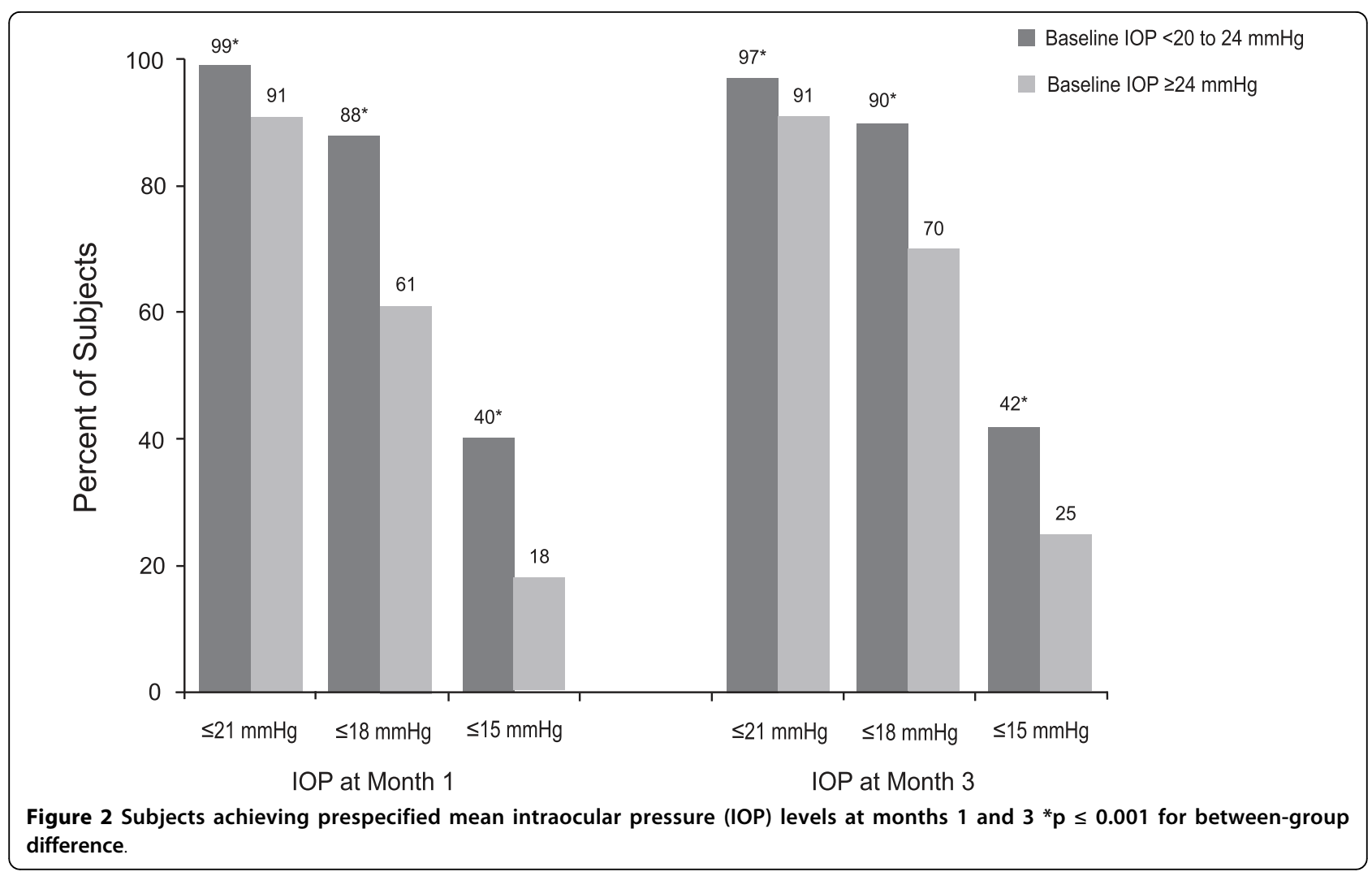

Table 3 Summary of adverse events, safety population $(\mathrm{N}=590) *$

\begin{tabular}{lcc}
\hline & \multicolumn{2}{c}{ Baseline Intraocular Pressure } \\
\hline Subjects with: & 20 to $<24 \mathrm{mmHg} \mathrm{N}=262$ & $\geq 24 \mathrm{mmHg} \mathrm{N}=328$ \\
\cline { 2 - 3 }$\geq 1$ adverse event & $126(38.4)[180]$ \\
$\geq 1$ treatment-related adverse event ${ }^{\dagger}$ & $111(42.4)[159]$ & $99(30.2)[126]$ \\
$\geq 1$ serious adverse event & $83(31.7)[109]$ & $4(1.2)[5]$ \\
$\geq 1$ adverse event leading to treatment discontinuation & $5(1.9)[5]$ & $5(2.4)[13]$ \\
\hline
\end{tabular}

${ }^{*} \mathrm{n}(\%)$ of subjects [number of events].

${ }^{\dagger}$ Patient-reported use of a bottle of latanoprost beyond its expiration date, i.e., for $>28$ days after opening, was reported by 54 subjects in the 20 to $<24$ mmHg group and by 65 subjects in the $\geq 24 \mathrm{mmHg}$ group. These were counted as adverse events and as treatment-related adverse events. No other ocular or systemic adverse event was associated with extended use in any subject.

to timolol administered twice daily [9-13] and to be as effective and as safe as other frequently prescribed prostaglandin analogues [15-17]. In an observational study [18] of patients switched to latanoprost from previous glaucoma therapies, mean IOP was reduced from $21.3 \pm$ 4.1 to $17.6 \pm 3.2 \mathrm{mmHg}$ in 1376 individuals followed for 2 years; the most common ocular adverse event was ocular irritation, noted in $1.6 \%$ of patients, while hyperemia was reported in $0.3 \%$. A 5 -year, open-label, safety surveillance study [19] included 5854 patients on IOPreducing therapy other than latanoprost who required a change in therapy and who were randomly assigned to latanoprost or usual care (any other commercially available ocular hypotensive therapy). In both groups, serious adverse drug reactions were reported in approximately
$0.4 \%$ of patients, and new occurrences of corneal erosions, iritis/uveitis, and macular edema were rare (risk $\leq$ $3.2 \%$ for each).

The present prospective, observational study extends these findings to "real world" treatment -naïve patients. We found first-line treatment with latanoprost to be effective and safe in ocular hypertension and open-angle glaucoma patients with pretreatment IOP levels in both the 20 to $<24 \mathrm{mmHg}$ range and $\geq 24 \mathrm{mmHg}$. Treatment response was rapid, seen within 1 month of initiating therapy, and was maintained throughout the follow-up period.

As would be expected, absolute and percentage IOP reductions were greater in the higher IOP stratum. Others [13,20-22] have observed that higher baseline 
Table 4 Number (\%) of treatment-related ocular adverse events $(N=590)$

\begin{tabular}{lcc}
\hline \multirow{2}{*}{ Subjects with: } & \multicolumn{2}{c}{ Baseline Intraocular Pressure } \\
\cline { 2 - 3 } & $\begin{array}{c}20 \text { to }<24 \mathrm{mmHg} \\
\mathrm{N}=262\end{array}$ & $\begin{array}{c}\geq 24 \mathrm{mmHg} \\
\mathrm{N}=328\end{array}$ \\
\hline Hyperemia & $28(10.7)$ & $28(8.5)$ \\
Eye pain & $8(3.1)$ & $11(3.4)$ \\
Blepharitis & $3(1.2)$ & $1(0.3)$ \\
Eyelid pruritis & $3(1.2)$ & $1(0.3)$ \\
Eye abnormality NOS & $2(0.8)$ & $2(0.6)$ \\
Keratitis & $2(0.8)$ & $2(0.6)$ \\
Eyelid edema & 0 & $3(0.9)$ \\
Photophobia & $1(0.4)$ & 0 \\
Vision abnormal NOS & 0 & $1(0.3)$ \\
Xerophthalmia & 0 & $1(0.3)$ \\
\hline
\end{tabular}

NOS $=$ not otherwise specified.

IOP levels are associated with greater IOP reductions, perhaps in part, due to regression to the mean, the tendency for an extreme value at first measurement to be closer to the center of the distribution at later measurement time points [23]. Nevertheless, significant responses to latanoprost therapy were seen in both IOP strata. For example, IOP levels $\leq 18 \mathrm{mmHg}$ were achieved by $90 \%$ and $70 \%$ of patients in the 20 to $<24$ and $\geq 24 \mathrm{mmHg}$ groups, respectively, at month 3 , and treatment response $(\geq 30 \%$ IOP reduction from baseline to month 3) was observed in nearly one half and in two-thirds of patients, respectively. In this population of treatment-naïve patients, the percentage of responders in both groups was greater than the $30 \%$ which generally could be expected with prostaglandin monotherapy [24]. Moreover, more than $94 \%$ of patients in each stratum achieved $\geq 10 \%$ IOP reductions from baseline to month 3 , a result consistent with that of a pooled-analysis of eight studies that found IOP reductions of $>15 \%$ in $93 \%$ of glaucoma and ocular hypertension patients without prior glaucoma treatment other than prostaglandins after 3 to 6 months of latanoprost therapy [13].

In the multivariate model, IOP stratum and myopia were found to significantly predict treatment response while other candidate variables including age, gender, diagnosis, and family history did not. The predictive value of IOP stratum reflects the positive relationship between baseline IOP level and IOP reduction discussed above. It has been suggested that IOP reductions associated with latanoprost use could be greater in myopic eyes since a larger area of trabecular meshwork might be found in eyes with negative spherical equivalence [13]. We cannot explain our opposite finding that myopia was negatively associated with a treatment response. It is possible, however, that the relatively low proportion of patients in the higher myopia categories affected the results. Multivariate analyses in populations with a more even distribution of patients with myopia are needed.

As reported by previous researchers [9-13,15], latanoprost was safe and well tolerated with no important differences between IOP strata. Conjunctival hyperemia was the most frequently reported ocular adverse event, occurring in $9 \%$ of patients overall. In general, hyperemia is the most common adverse event associated with prostaglandin use [25-27]. More than one third of adverse events overall and one half of treatment-related adverse events reflected patient reports of instillation of latanoprost from bottles that had been opened for $>28$ days.

Previous research has demonstrated that substantial reductions in IOP levels $[6-8,28]$ and, in particular, reductions to levels of $<18 \mathrm{mmHg}$ [5] delay or stop glaucomatous progression. For example, the Collaborative Initial Glaucoma Treatment Study [8] found that aggressive medical treatment resulting in diurnal IOP reductions of $\geq 35 \%$ from baseline virtually halted glaucomatous progression over 5 years, and treated patients in the Early Manifest Glaucoma Trial [7] had half the progression risk of untreated patients. Based on such findings, clinicians are encouraged when making treatment decisions to consider the likelihood of achieving a predetermined target IOP level or percentage IOP reduction consistent with the patient's disease status [24,29].

The relative convenience and side effect profiles of therapies also may be important factors in treatment decision making. More complex medication dosing schedules have been shown to negatively impact adherence in glaucoma patients [3,30-32]. Patients in the present study reported very high levels of treatment compliance with latanoprost. Although these compliance rates may to some extent reflect 'white-coat adherence' $[33,34]$, patients prescribed once-daily prostaglandin analogues have been found to be more compliant [35] and to remain on treatment significantly longer [36-38] than those prescribed other classes of medication, including beta-blockers. Moreover, patients prescribed latanoprost are more persistent with therapy than those prescribed either bimatoprost or travoprost [37]. Ocular adverse events, especially hyperemia which is less common with latanoprost than with the other prostaglandin analogues, have been shown to negatively impact patient continuation with therapy [39].

The present study has a number of important strengths. First, findings of this prospective, open-label, uncontrolled, observational study better reflect actual clinical practice conditions than those based on randomized, controlled trials and therefore may be more generalizable to routine ophthalmology practices. Although the target of enrolling 768 subjects was not reached, the 
fact that 600 treatment-naive subjects were enrolled makes this, to our knowledge, the largest study of the effectiveness and safety of first-line latanoprost conducted to date. An additional strength is the study's inclusion of a multivariate model to evaluate potential predictors of treatment response.

The study's limitations include the fact that some investigators measured IOP levels using air-pulse tonometry while others used Goldmann applanation tonometry; ideally, all would have used the latter method. The relative infrequency of presentation by treatment-naive ocular hypertension or open-angle glaucoma patients to clinical practices necessitated the inclusion of a large number of centers to ensure timely subject recruitment; the impact on findings of interpractice variation in recording information and/or in treatment standards and practices is not known. Reflecting the study's observational, "real world" approach, investigators did not routinely record all variables of potential interest, such as central corneal thickness. In addition, the method used to measure IOP levels was not always documented making it infeasible to analyze IOP changes stratified by tonometry type. Finally, future research should include a larger population of treatment-naïve patients followed over a longer time period in order to ensure detection of rare but potentially serious adverse events; it is notable, however, that a large 5-year safety study [19] found rates of new cases of corneal erosions, iritis/uveitis, or macular edema to be low and similar in those treated with latanoprost or other approved ocular hypotensive therapies. A study with a larger patient population also would support an analysis of risk factors for nonresponse to latanoprost.

\section{Conclusions}

This 3-month, open-label, multicenter, uncontrolled, phase IV, "real world" study found monotherapy with once-daily latanoprost to be effective and safe in treatment-naive ocular hypertension or open-angle glaucoma patients. Patients with baseline IOP levels of 20 to $<24$ $\mathrm{mmHg}$ as well as $\geq 24 \mathrm{mmHg}$ benefitted from initial latanoprost treatment.

\footnotetext{
Acknowledgements

The study was supported by Pfizer France.

The results of this study were presented in part at the 17th Congress of the European Society of Ophthalmology (SOE 2009) June 13-16, 2009 in Amsterdam, Netherlands.

Editorial support, including revising the paper and styling the paper for journal submission, was provided by Jane G. Murphy, PhD, of Zola Associates. Richard A. Siegel, PhD, an independent consultant, critically reviewed the manuscript. Funding was provided by Pfizer France.
}

\footnotetext{
Author details

'Ophthalmology Department, Hôpital Edouard Herriot, 5, Place d'Arsonval, 690437 Lyon Cedex 03, France. ${ }^{2}$ Ophthalmology Department 3, Centre
}

Hospitalier National des Quinze-Vingts, 28, Rue de Charenton, Paris Cedex 12, France. ${ }^{3}$ Ophthalmology Department, Hôpital Général, 3, Rue du Faubourg Raines, 21033 Dijon, France. ${ }^{4}$ Ophthalmology Department 2, Centre Hospitalier National des Quinze-Vingts, 28, Rue de Charenton, Paris Cedex 12, France. ${ }^{5}$ Ophthalmology Department, Hôpital d'Instruction des Armées du Val de Grâce, 74, Boulevard du Port Royal, Paris Cedex 05, France. ${ }^{6}$ Ophthalmology Department, Hôpital Huriez, 1, Place de Verdun, 59037 Lille, France. ${ }^{7}$ Centre Ophtalmologique Kléber, 50, Cours Franklin Roosevelt, 69006 Lyon, France. ${ }^{8} 1$ allée Giuseppe Verdi, 94350 Villiers Sur Marne, France.

\section{Authors' contributions}

PD participated in the study design, analysis and interpretation of data, drafting of the manuscript, critical revision of the manuscript for important intellectual content, and study supervision. CB participated in the study design, analysis and interpretation of data, and critical revision of the manuscript for important intellectual content. AB, JPN, and JPR participated in the study design, acquisition of data, and critical revision of the manuscript for important intellectual content. JFR and ES participated in the study design and critical revision of the manuscript for important intellectual content. MA participated in the analysis and interpretation of data, critical revision of the manuscript for important intellectual content, and study supervision. All authors read and approved the final manuscript.

\section{Competing interests}

Dr. Amrane was an employee of Pfizer Inc at the time the study was conducted. The remaining authors have no proprietary interests.

Received: 9 September 2009

Accepted: 24 February 2010 Published: 24 February 2010

\section{References}

1. Resnikoff S, Pascolini D, Etya'ale D, Kocur I, Pararajasegaram R, Pokharel GP, Mariotti SP: Global data on visual impairment in the year 2002. Bull World Health Organ 2004, 82:844-851.

2. Friedman DS, Wilson MR, Liebmann JM, Fechtner RD, Weinreb RN: An evidence-based assessment of risk factors for the progression of ocular hypertension and glaucoma. Am J Ophthalmol 2004, 138(3 Suppl):S19-31.

3. Kass MA, Gordon M, Morley RE Jr, Meltzer DW, Goldberg JJ: Compliance with topical timolol treatment. Am J Ophthalmol 1987, 103:188-193.

4. Leske MC, Heijl A, Hyman L, Bengtsson B, Dong L, Yang Z, EMGT Group: Predictors of long-term progression in the early manifest glaucoma trial. Ophthalmology 2007, 114:1965-1972.

5. The AGIS Investigators: The Advanced Glaucoma Intervention Study (AGIS): 7. The relationship between control of intraocular pressure and visual field deterioration. Am J Ophthalmol 2000, 130:429-440.

6. Heijl A, Leske MC, Bengtsson B, Hyman L, Bengtsson B, Hussein M, Early Manifest Glaucoma Trial Group: Reduction of intraocular pressure and glaucoma progression: results from the Early Manifest Glaucoma Trial. Arch Ophthalmol 2002, 120:1268-1279.

7. Leske MC, Heijl A, Hussein M, Bengtsson B, Hyman L, Komaroff E, Early Manifest Glaucoma Trial Group: Factors for glaucoma progression and the effect of treatment: the Early Manifest Glaucoma Trial. Arch Ophthalmol 2003, 121:48-56.

8. Lichter PR, Musch DC, Gillespie BW, Guire KE, Janz NK, Wren PA, Mills RP, CIGTS Study Group: Interim clinical outcomes in the Collaborative Initial Glaucoma Treatment Study comparing initial treatment randomized to medications or surgery. Ophthalmology 2001, 108:1943-1953.

9. Alm A, Stjernschantz J: Effects on intraocular pressure and side effects of $0.005 \%$ latanoprost applied once daily, evening or morning. A comparison with timolol. Scandinavian Latanoprost Study Group. Ophthalmology 1995, 102:1743-1752.

10. Camras CB: Comparison of latanoprost and timolol in patients with ocular hypertension and glaucoma: a six-month masked, multicenter trial in the United States. Ophthalmology 1996, 103:138-147.

11. Watson P, Stjernschantz J: A six-month, randomized, double-masked study comparing latanoprost with timolol in open-angle glaucoma and ocular hypertension. Ophthalmology 1996, 103:126-137.

12. Varma R, Hwang LJ, Grunden JW, Bean GW, Sultan MB: Assessing the efficacy of latanoprost vs timolol using an alternate efficacy parameter: the intervisit intraocular pressure range. Am J Ophthalmol 2009, 148:221-226. 
13. Hedman K, Larsson Ll: The effect of latanoprost compared with timolol in African-American, Asian, Caucasian, and Mexican open-angle glaucoma or ocular hypertensive patients. Surv Ophthalmol 2002, 47(Suppl 1):S77-89.

14. Collaborative Normal-Tension Glaucoma Study Group: Comparison of glaucomatous progression between untreated patients with normaltension glaucoma and patients with therapeutically reduced intraocular pressures. Am J Ophthalmol 1998, 126:487-497.

15. Parrish RK, Palmberg P, Sheu WP, XLT Study Group: A comparison of latanoprost, bimatoprost, and travoprost in patients with elevated intraocular pressure: a 12-week, randomized, masked-evaluator multicenter study. Am J Ophthalmol 2003, 135:688-703.

16. Orzalesi N, Rossetti L, Bottoli A, Fogagnolo P: Comparison of the effects of latanoprost, travoprost, and bimatoprost on circadian intraocular pressure in patients with glaucoma or ocular hypertension. Ophthalmology 2006, 113:239-246.

17. Yildirim N, Sahin A, Gultekin S: The effect of latanoprost, bimatoprost, and travoprost on circadian variation of intraocular pressure in patients with open-angle glaucoma. J Glaucoma 2008, 17:36-39.

18. Bayer A, Weiler W, Oeverhaus U, Skrotzki FE, Stewart WC, the XPLORE Observation Group: Two-year follow-up of latanoprost $0.005 \%$ monotherapy after changing from previous glaucoma therapies. J Ocul Pharmacol Ther 2004, 20:470-478.

19. Goldberg I, Li XY, Selaru P, Paggiarino D: A 5-year, randomized, open-label safety study of latanoprost and usual care in patients with open-angle glaucoma or ocular hypertension. Eur J Ophthalmol 2008, 18:408-416.

20. Hedman K, Alm A: A pooled-data analysis of three randomized, doublemasked, six-month clinical studies comparing the intraocular pressure reducing effect of latanoprost and timolol. Eur J Ophthalmol 2000, 10:95-104.

21. Ang A, Reddy MA, Shepstone L, Broadway DC: Long term effect of latanoprost on intraocular pressure in normal tension glaucoma. $\mathrm{Br} J$ Ophthalmol 2004, 88:630-634.

22. Rulo AH, Greve EL, Geijssen HC, Hoyng PF: Reduction of intraocular pressure with treatment of latanoprost once daily in patients with normal-pressure glaucoma. Ophthalmology 1996, 103:1276-1282.

23. Dawson-Saunders B, Trapp RB: Basic and Clinical Biostatistics. Norwalk, CT: Appleton \& Lange 1990.

24. European Glaucoma Society Terminology and Guidelines for Glaucoma. Savona, Italy: DOGMA, II 2008http://www.eugs.org/eng/default.asp, Accessed: March 12, 2009.

25. Lumigan [package insert]: Irvine, Calif: Allergan, Inc 2006.

26. Travatan [package insert]: Fort Worth, Tex: Alcon Laboratories, Inc 2005.

27. Xalatan [package insert]: New York, NY: Pfizer Inc 2003.

28. Kass MA, Heuer DK, Higginbotham EJ, Johnson CA, Keltner JL, Miller JP, Parrish RK, Wilson MR, Gordon MO: The Ocular Hypertension Treatment Study: a randomized trial determines that topical ocular hypotensive medication delays or prevents the onset of primary open-angle glaucoma. Arch Ophthalmol 2002, 120:701-713.

29. Coleman AL, Caprioli J: The logic behind target intraocular pressure. Am J Ophthalmol 2009, 147:379-380.

30. Olthoff CM, Schouten JS, Borne van de BW, Webers CA: Noncompliance with ocular hypotensive treatment in patients with glaucoma or ocular hypertension an evidence-based review. Ophthalmology 2005, 112:953-961.

31. Gurwitz JH, Glynn RJ, Monane M, Everitt DE, Gilden D, Smith N, Avorn J: Treatment for glaucoma: adherence by the elderly. Am J Public Health 1993, 83:711-716.

32. Robin AL, Novack GD, Covert DW, Crockett RS, Marcic TS: Adherence in glaucoma: objective measurements of once-daily and adjunctive medication use. Am J Ophthalmol 2007, 144:533-540.

33. Krousel-Wood M, Thomas S, Muntner P, Morisky D: Medication adherence: a key factor in achieving blood pressure control and good clinical outcomes in hypertensive patients. Curr Opin Cardiol 2004, 19:357-362.

34. Feinstein AR: On white-coat effects and the electronic monitoring of compliance. Arch Intern Med 1990, 150:1377-1378.

35. Nordstrom BL, Friedman DS, Mozaffari E, Quigley HA, Walker AM: Persistence and adherence with topical glaucoma therapy. Am $J$ Ophthalmol 2005, 140:598-606.

36. Reardon G, Schwartz GF, Mozaffari E: Patient persistency with pharmacotherapy in the management of glaucoma. Eur J Ophthalmol 2003, 13(Suppl 4):S44-52.
37. Reardon G, Schwartz GF, Mozaffari E: Patient persistency with ocular prostaglandin therapy: a population-based, retrospective study. Clin Ther 2003, 25:1172-1185.

38. Schwartz GF, Reardon G, Mozaffari E: Persistency with latanoprost or timolol in primary open-angle glaucoma suspects. Am J Ophthalmol 2004, 137(1 Suppl):S13-16.

39. Zimmerman TJ, Hahn SR, Gelb L, Tan H, Kim EE: The impact of ocular adverse effects in patients treated with topical prostaglandin analogs: change in prescription patterns and patient persistence. J Ocul Pharmacol Ther 2009, 25:145-152.

\section{Pre-publication history}

The pre-publication history for this paper can be accessed here:http://www biomedcentral.com/1471-2415/10/4/prepub

\section{doi:10.1186/1471-2415-10-4}

Cite this article as: Denis et al:: First-line latanoprost therapy in ocular hypertension or open-angle glaucoma patients: a 3-month efficacy analysis stratified by initial intraocular pressure. BMC Ophthalmology 2010 10:4

\section{Submit your next manuscript to BioMed Central and take full advantage of:}

- Convenient online submission

- Thorough peer review

- No space constraints or color figure charges

- Immediate publication on acceptance

- Inclusion in PubMed, CAS, Scopus and Google Scholar

- Research which is freely available for redistribution 